\title{
ДИАГНОСТИКА КАЧЕСТВА ОБУЧЕНИЯ БОЛЬНЫХ БРОНХИАЛЬНОЙ АСТМОЙ В ПРОФЕССИОНАЛЬНОЙ ДЕЯТЕЛЬНОСТИ ВРАЧА АЛЛЕРГОЛОГА-ИММУНОЛОГА
}

\author{
Ганцева Х.Х., Ханова А.К., Явгильдина А.М.
}

Статья посвящена диагностике качества обучения паџиентов с бронхиальной астмой.

Цель. Разработка объективного способа оценки качества проведения образовательных программ для пачиентов с бронхиальной астмой к обеспечению процедур самоконтроля и комплаенса с лечащим врачом.

Материалы и методы. Данное исследование проводилось на территории Республики Башкортостан с разрешения этического комитета ФГБОУ ВО БГМУ Минздрава РФ. Каждый участник перед началом исследования подписал форму информированного согласия на обследование.

Анкетным методом, включающим 140 признаков, отражающих владения теоретическими знаниями и владение практическими умениями, требуемых к завершению обучения в "Астме-иколе», где каждый показатель оценивается в баллах, и совокупный их уровень дает итоговый, заключающий оченочный уровень с интерпретацией 3 блоков вопросов.

Результаты. Вопросы первого блока имеют градачии: хорочее знание, удовлетворительное знание, незнание: второго блока-хоромее владение навыком, удовлетворительное, отсутствие навыка; в третьем блоке - оценка клинических проявлений заболевания, используемых в совокупности самооченки паџиентом качества жизни как высокая, средняя и низкая. Суммируя полученные баллы от каждого из 140 использованных в исследовании признаков, при количестве баллов от 40 до 66, оченивали уровень знаний, навыков пачиентов как низкий, 67-93 - как средний, 94-120 - как высокий. Приведены 2 клинических примера из практики их использования в реальной ситуации.

Заключение. Предлагаемая методика оченки качества обучения паииентов «Астма-иколь»» позволяет объективизировать результать образовательного процесса относительно пациентов и модернизировать, 
повысить эффективность работы врача с паџиентами бронхиальной астмой.

Ключевые слова: бронхиальная астма; астма-школа; образовательные программы для пациентов; здоровьесберегающие технологии; качество жизни; клинико-экономическая эффективность.

\section{DIAGNOSTICS OF QUALITY \\ TRAINING PATIENTS WITH BRONCHIAL ASTHMA \\ IN PROFESSIONAL ACTIVITY OF A DOCTOR ALLERGOLOGIST-IMMUNOLOGY}

\section{Gantseva Kh.Kh., Khanova A.K., Yavgildina A.M.}

The article is devoted to the diagnosis of the quality of education for patients with bronchial asthma.

Goal. Development of an objective way to assess the quality of educational programs for patients with bronchial asthma to ensure self-control and compliance procedures with the attending physician.

Materials and methods. This study was conducted on the territory of the Republic of Bashkortostan with the permission of the ethics committee of the FSBEI HE BSMU of the Ministry of Health of the Russian Federation. Each participant before the start of the study signed an informed consent form for the examination.

The questionnaire method, which includes 140 signs, reflecting the possession of theoretical knowledge and the possession of practical skills required to complete studies at Asthma School, where each indicator is evaluated in points, and their combined level gives a final, concluding assessment level with interpretation of 3 blocks of questions.

Results. The questions of the first block have the gradations: good knowledge, satisfactory knowledge, ignorance: of the second block-good knowledge of the skill, satisfactory, lack of skill; in the third block - an assessment of the clinical manifestations of the disease used in the aggregate of the patient's self-assessment of the quality of life as high, medium and low. Summing up the scores from each of the 140 signs used in the study, with the number of points from 40 to 66, the level of knowledge and skills of the patients was assessed as low, 67-93 as average, 94-120 as high. 2 clinical examples from the practice of their use in a real situation are given. 
Conclusion. The proposed methodology for assessing the quality of patient education at Asthma Schools makes it possible to objectify the results of the educational process in relation to patients and to modernize and increase the efficiency of the doctor's work with patients with bronchial asthma.

Keywords: bronchial asthma; asthma-school; educational programs for patients; health-saving technologies; quality of life; clinical and economic efficiency.

\section{Актуальность}

В России на протяжении последних десятилетий расширяется сеть школ здоровья для разных групп населения, разрабатываются технологии психологического сопровождения их функционирования. Все большая роль отводится программам обучения пациентов с целью повышения их информированности и активного вовлечения в оздоровительный, лечебно-диагностический и реабилитационный процесс.

В частности, тезис «разработка и внедрение образовательных программ среди населения по методам профилактики бронхиальной астмы, формирования здорового образа жизни и повышения качества жизни пациентов» является одним из основных в проекте Федеральной Целевой программы «Бронхиальная астма» (2011-2015 годы). Эффективность терапии бронхиальной астмы, улучшение качества жизни пациентов и их семей тесно связаны с тщательным выполнением квалифицированных врачебных рекомендаций. Образование является необходимой составной частью комплексной программы лечения пациентов с бронхиальной астмой. В настоящее время одной из самых эффективных форм проведения образования для больных считается «Астма-школа». Основной ее целью является повышение эффективности терапии бронхиальной астмы, обеспечение контроля за течением болезни и повышение качества жизни посредством образования самого пациента.

Участие пациентов в образовательной программе позволяет сформировать у них правильное представление о здоровьесберегающих технологиях, болезни, о факторах риска ее возникновения и причинах прогрессирования, о методах самоконтроля, что позволяет более четко выполнять комплекс рекомендаций в течение длительного времени $[1,8]$.

Глембицкая А.И. и соавт. (2011 г.) показали, что применение этой медицинской технологии снижает прямые и непрямые расходы на лечение бронхиальной астмы за счет уменьшения финансовых потерь, связанных с оказанием различных видов медицинских услуг (вызовы скорой медицинской помощи, оплата больничных листков и потерь валового внутреннего продукта в результате болезни) и повышает эффективность затрат до 5-7 
раз [2]. Таким образом, применение обучающих программ имеет не только медицинское, но и социально-экономическое значение, способствует лучшей социальной адаптации пациентов с хронической патологией, что ведет к уменьшению прямых и косвенных затрат на лечение [3].

Отсутствие мотивации у пациентов к постоянной терапии связано с недостаточностью имеющейся информации о своем заболевании, отсутствием навыков самоконтроля, элементарной грамотности в приеме лекарств, в сочетании с неудовлетворительным качеством амбулаторного наблюдения за данной категорией пациентов [4].

В доступной нам научно-методической и патентной литературе способ оценки качества обучения в рамках «Астма-школы» по уровню знаний обучающихся пациентов не описан.

Известен способ контроля над астмой - вопросник «АCT» (Asthma Control Test), состоящий из 5 вопросов, который предназначен для самостоятельной оценки пациентом своего состояния, чтобы вовремя обратиться к врачу при ухудшении течения болезни $[5,6,7]$. Однако этот тест является сугубо клиническим и не позволяет оценить уровень компетентности пациентов в вопросах контроля над бронхиальной астмой.

Таким образом, до настоящего времени не определен способ оценки уровня компетентности пациентов, обучающихся в «Астма-школе», что обусловлено отсутствием «обратной связи» между обучающим врачом и обучаемыми пациентами.

\section{Цель исследования}

Обоснование объективного способа оценки качества проведения образовательных программ для пациентов, страдающих бронхиальной астмой.

В основе предлагаемого метода лежит оценка уровня теоретических знаний, усвоенных практических навыков и умений, способных оказать влияние на качество жизни пациентов и течение основного заболевания, а также динамика течения заболевания по объективизированным статистическим медицинским критериям $[8,9]$.

Ожидаемый результат при использовании методического приема - получение критериев оценки качества реализации образовательной программы в рамках «астма-школы».

\section{Материалы и методы}

Приказ Минздравсоцразвития России № 60 от 4.02.2010 г. «О порядке оказания медицинской помощи больных с аллергическими заболевания- 
ми», обязует проведение обучающих программ для пациентов с аллергическими заболеваниями.

Авторами была проведена работа по выделению прогностически значимых факторов, позволяющих оценить качество обучения пациентов, прошедших обучение в «Астма-школе». Были исследованы 140 признаков, которые могли наиболее полно отразить уровень овладения теоретическими знаниями и приобретения практических навыков и умений в процессе обучения в «Астма-школе». Основными требованиями к данным признакам явилась объективность, доступность их оценки пациентами и простота получения.

Изучение требуемых признаков проведено у 80 пациентов. С целью выделения наиболее значимых признаков, отражающих уровень информированности пациентов, полученные данные были подвергнуты математической обработке и оценены экспертным советом обучающих врачей-аллергологов. Из анкеты были исключены вопросы, вызвавшие наибольшие затруднения у пациентов и наименее информативные с точки зрения экспертного совета. На основании полученных данных были выбраны 40 наиболее значимых и информативных признаков.

\section{Результаты исследования и их обсуждение}

Предлагаемый методический прием осуществляется следующим образом. Для оценки качества проведенного обучения в рамках «Астма-школы» проводится оценка уровня теоретических знаний, усвоенных практических навыков и умений, способных оказать влияние на качество жизни пациентов и течение основного заболевания. Для этого проводится анкетирование пациентов по анкете, состоящей из 3 блоков вопросов. Первый блок вопросов касается теоретических знаний, полученных в процессе обучения в «Астма-школе», второй блок вопросов оценивает уровень приобретенных практических навыков и умений и третий блок вопросов уточняет динамику течения заболевания по объективизированным статистическим медицинским критериям.

При этом устанавливаются и выписываются на отдельный лист показатели информированности пациентов: по вопросам первого блока знание анатомического строения органов дыхания, физиологии дыхания (1), знание собственных антропометрических показателей - роста, массы тела (2), знание собственных показателей гемодинамики - пульса, уровня артериального давления (3), знание всех управляемых факторов риска формирования и обострения астмы (4), знание признаков обострения забо- 
левания (5), знание принципов клинико-функционального самоконтроля за течением астмы (6), знание назначения таких приборов индивидуального пользования, как спейсер и пикфлоуметр (7), знание принципов элиминационной терапии заболевания (8), знание современных лекарственных препаратов и методов лечения бронхиальной астмы (9), знание ингаляционных устройств для лечения астмы (10), знание принципов здорового образа жизни (11), знание основ диетотерапии больного бронхиальной астмой (12), знание принципов дыхательной гимнастики и физкультуры для больных бронхиальной астмой, закаливания (13), знание основ общего массажа и массажа лица (14); вопросы второго блока по уровню приобретенных практических навыков и умений - владение навыком по подсчету пульса (15), владение навыками по подсчету частоты дыхания (16), уровень обучения оценки состояния по системе цветовых «зон» (17), владение техникой пикфлоуметрии (18), умение интерпретации результатов диагностических процедур (19), способность пациента самостоятельно предотвращать приближающееся ухудшение в течении астмы (20), владение техникой ингаляций при использовании дозированных ингаляторов, спейсеров, небулайзеров (21), уровень ведения дневника самонаблюдения (22), владение навыками по дыхательным методикам по методу биологически обратной связи (23), владение навыками по волевому управлению дыханием (24), владение элементами самомассажа биологически активных точек для активного использования в приступном периоде наряду с дыхательной гимнастикой (25), владение навыками мышечной релаксации (26), владение элементами аутотренинга (27), владение психотерапевтическими приемами (28), навыки по лечебной физкультуре (29), навыки по составлению домашней аптечки (30); навыки саногенного поведения (31), вопросы третьего блока по динамике течения заболевания согласно объективизированным статистическим медицинским критериям - частота дневных приступов удушья (32), частота ночных приступов удушья (33), частота обострений (34), частота госпитализаций в стационар (35), число дней временной нетрудоспособности (36), число вызовов бригады «скорой помощи» (37), инвалидизация (38), оценка общего состояния (39), самооценка качества жизни (40).

Каждый показатель оценивается в баллах. Вопросы первого блока по уровню знаний оценивали следующим образом: хорошее знание анатомического строения органов дыхания, физиологии дыхания оценивают как 3 балла, удовлетворительное - как 2 балла, незнание - как 1 балл; хорошее знание собственных антропометрических показателей - роста, 
массы тела оценивают как 3 балла, удовлетворительное знание - как 2 балла, незнание - как 1 балл; хорошее знание собственных показателей гемодинамики - пульса, уровня артериального давления оценивают как 3 балла, удовлетворительное знание - как 2 балла, незнание - как 1 балл; хорошее знание всех управляемых факторов риска формирования и обострения астмы оценивают как 3 балла, удовлетворительное знание - как 2 балла, незнание - как 1 балл; хорошее знание признаков обострения заболевания оценивают как 3 балла, удовлетворительное знание - как 2 балла, незнание - как 1 балл; хорошее знание принципов клинико-функционального самоконтроля за течением астмы оценивают как 3 балла, удовлетворительное знание - как 2 балла, незнание - как 1 балл; хорошее знание назначения таких приборов индивидуального пользования, как спейсер и пикфлоуметр оценивают как 3 балла, удовлетворительное знание - как 2 балла, незнание - как 1 балл; хорошее знание принципов элиминационной терапии заболевания оценивают как 3 балла, удовлетворительное знание - как 2 балла, незнание - как 1 балл; хорошее знание современных лекарственных препаратов и методов лечения бронхиальной астмы оценивают как 3 балла, удовлетворительное знание - как 2 балла, незнание - как 1 балл; хорошее знание ингаляционных устройств для лечения астмы оценивают как 3 балла, удовлетворительное знание - как 2 балла, незнание - как 1 балл; хорошее знание принципов здорового образа жизни оценивают как 3 балла, удовлетворительное знание - как 2 балла, незнание - как 1 балл; хорошее знание основ диетотерапии больного бронхиальной астмой оценивают как 3 балла, удовлетворительное знание - как 2 балла, незнание - как 1 балл; хорошее знание принципов дыхательной гимнастики и физкультуры для больных бронхиальной астмой, закаливания оценивают как 3 балла, удовлетворительное знание - как 2 балла, незнание - как 1 балл; хорошее знание основ общего массажа и массажа лица оценивают как 3 балла, удовлетворительное знание - как 2 балла, незнание - как 1 балл.

Вопросы второго блока по уровню приобретенных практических навыков и умений оценивали так: хорошее владение навыком по подсчету пульса оценивают как 3 балла, удовлетворительное - как 2 балла, отсутствие навыка - как 1 балл; хорошее владение навыками по подсчету частоты дыхания оценивают как 3 балла, удовлетворительное - как 2 балла, отсутствие навыка - как 1 балл; хороший уровень обучения оценки состояния по системе цветовых «зон» оценивают как 3 балла, удовлетворительное как 2 балла, отсутствие навыка - как 1 балл; хорошее владение техникой 
пикфлоуметрии оценивают как 3 балла, удовлетворительное как 2 балла, отсутствие навыка - как 1 балл; хорошее умение интерпретации результатов диагностических процедур оценивают как 3 балла, удовлетворительное - как 2 балла, отсутствие навыка - как 1 балл; хорошую способность пациента самостоятельно предотвращать приближающееся ухудшение в течении астмы оценивают как 3 балла, удовлетворительное - как 2 балла, отсутствие навыка - как 1 балл; хорошее владение техникой ингаляций при использовании дозированных ингаляторов, спейсеров, небулайзеров оценивают как 3 балла, удовлетворительное - как 2 балла, отсутствие навыка - как 1 балл; хороший уровень ведения дневника самонаблюдения оценивают как 3 балла, удовлетворительное - как 2 балла, отсутствие навыка - как 1 балл; хорошее владение навыками по дыхательным методикам по методу биологически обратной связи оценивают как 3 балла, удовлетворительное - как 2 балла, отсутствие навыка - как 1 балл; хорошее владение навыками по волевому управлению дыханием оценивают как 3 балла, удовлетворительное - как 2 балла, отсутствие навыка - как 1 балл; хорошее владение элементами самомассажа биологически активных точек для активного использования в приступном периоде наряду с дыхательной гимнастикой оценивают как 3 балла, удовлетворительное как 2 балла, отсутствие навыка - как 1 балл; хорошее владение навыками мышечной релаксации оценивают как 3 балла, удовлетворительное - как 2 балла, отсутствие навыка - как 1 балл; хорошее владение элементами аутотренинга оценивают как 3 балла, удовлетворительное - как 2 балла, отсутствие навыка - как 1 балл; хорошее владение психотерапевтическими приемами оценивают как 3 балла, удовлетворительное - как 2 балла, отсутствие навыка - как 1 балл; хорошие навыки по лечебной физкультуре оценивают как 3 балла, удовлетворительное - как 2 балла, отсутствие навыка - как 1 балл; хорошие навыки по составлению домашней аптечки оценивают как 3 балла, удовлетворительное - как 2 балла, отсутствие навыка - как 1 балл; хорошие навыки саногенного поведения оценивают как 3 балла, удовлетворительное - как 2 балла, отсутствие навыка - как 1 балл.

Вопросы третьего блока по динамике течения заболевания согласно объективизированным статистическим медицинским критериям оценивали следующим образом: отсутствие дневных приступов удушья оценивают как 3 балла, редкие приступы - как 2 балла, частые приступы - как 1 балл; отсутствие ночных приступов удушья оценивают как 3 балла, редкие приступы - как 2 балла, частые приступы - как 1 балл; отсутствие обострений оценивают как 3 балла, 1-2 обострений - как 2 балла, более 2 обострений - 
как 1 балл; отсутствие госпитализаций в стационар оценивают как 3 балла, 1 госпитализация - как 2 балла, 2 и более - как 1 балл; отсутствие случаев временной нетрудоспособности оценивают как 3 балла, до 14 дней нетрудоспособности - как 2 балла, более 14 дней - как 1 балл; отсутствие вызовов бригады «скорой помощи» - как 3 балла, 1-2 вызова - как 2 балла, более 2 раз - как 1 балл, уменьшение группы инвалидности или ее отсутствие - как 3 балла, сохранение той же группы инвалидности как 2 балла, утяжеление как 1 балл; значительное улучшение общего состояния - как 3 балла, без перемен - как 2 балла, ухудшение - как 1 балл, высокая самооценка качества жизни - как 3 балла, средняя - как 2 балла, низкая - как 1 балл.

Суммируют полученные баллы и при количестве баллов от 40 до 66 оценивали уровень знаний, навыков пациентов как низкий, 67-93 - как средний, 94-120 - как высокий.

Предлагаемый способ оценки был использован у 60 пациентов с бронхиальной астмой, прошедших обучение в «Астма-школе».

Полученные данные дают основание считать качество разработанной методики оценки достаточно высоким, что позволяет рекомендовать его для практического применения.

Предлагаемый способ оценки качества обучения пациентов «Астма-школы», основанный на анализе теоретических знаний, полученных в процессе обучения в «Астма-школе», владения практическими навыками и умениями, оценки динамики течения заболевания согласно объективизированным статистическим медицинским критериям позволяет оценить качество обучения пациента в «Астма-школе».

Клинический пример 1. Пациент С., 38 лет. В течение 12 месяцев страдает бронхиальной астмой. Прошел полный курс обучения в «Астма-школе» на базе муниципальной поликлиники.

После завершения учебного процесса с целью оценки эффективности реализации образовательной программы было проведено анкетирование.

Ответы на вопросы первого блока показали следующий уровень знаний: удовлетворительное знание анатомического строения органов дыхания, физиологии дыхания (2 балла), хорошее знание собственных антропометрических показателей - роста, массы тела (3 балла), хорошее знание собственных показателей гемодинамики - пульса, уровня артериального давления (3 балла), хорошее знание всех управляемых факторов риска формирования и обострения астмы (3 балла), хорошее знание признаков обострения заболевания (3 балла), удовлетворительное знание принципов клинико-функционального самоконтроля за течением астмы 
(2 балла), хорошее знание назначения таких приборов индивидуального пользования, как спейсер и пикфлоуметр (3 балла), хорошее знание принципов элиминационной терапии заболевания (3 балла), удовлетворительное знание современных лекарственных препаратов и методов лечения бронхиальной астмы (2 балла), хорошее знание ингаляционных устройств для лечения астмы (3 балла), хорошее знание принципов здорового образа жизни (3 балла), хорошее знание основ диетотерапии больного бронхиальной астмой (3 балла), хорошее знание принципов дыхательной гимнастики и физкультуры для пациентов с бронхиальной астмой, закаливания (3 балла), хорошее знание основ общего массажа и массажа лица (3 балла).

Анкетирование по вопросам второго блока по уровню приобретенных практических навыков и умений показало хорошее владение навыком по подсчету пульса (3 балла), хорошее владение навыками по подсчету частоты дыхания (3 балла), удовлетворительный уровень обучения оценки состояния по системе цветовых «зон» (2 балла), хорошее владение техникой пикфлоуметрии (3 балла), хорошее умение интерпретации результатов диагностических процедур (3 балла), удовлетворительная способность пациента самостоятельно предотвращать приближающееся ухудшение в течении астмы (2 балла), хорошее владение техникой ингаляций при использовании дозированных ингаляторов, спейсеров, небулайзеров (3 балла), хороший уровень ведения дневника самонаблюдения (3 балла), хорошее владение навыками по дыхательным методикам по методу биологически обратной связи (3 балла), хорошее владение навыками по волевому управлению дыханием (3 балла), хорошее владение элементами самомассажа биологически активных точек для активного использования в приступном периоде наряду с дыхательной гимнастикой (3 балла), хорошее владение навыками мышечной релаксации (3 балла), владение элементами аутотренинга (3 балла), удовлетворительное владение психотерапевтическими приемами (2 балла), хорошие навыки по лечебной физкультуре (3 балла), хорошие навыки по составлению домашней аптечки (3 балла); хорошие навыки саногенного поведения (3 балла).

Анкетирование по вопросам третьего блока по динамике течения заболевания согласно объективизированным статистическим медицинским критериям показало наличие редких приступов удушья (2 балла); редкие ночные приступы удушья (2 балла); отсутствие обострений (3 балла); отсутствие госпитализаций (3 балла); отсутствие случаев временной нетрудоспособности (3 балла); отсутствие вызовов бригады «скорой помощи» (3 балла), отсутствие группы инвалидности (3 балла); улучшение общего состояния (1 балл), средний уровень самооценки качества жизни (2 балла). 
Суммируя полученные результаты, получаем 108 баллов, что позволяет оценить высокий уровень подготовки пациента после завершения обучения в «Астма-школе».

Клинический пример 2. Пациент Р., 57 лет. В течение 18 месяцев страдает бронхиальной астмой. Прошел полный курс обучения в «астма-школе» на базе муниципальной поликлиники.

После завершения учебного процесса с целью оценки эффективности реализации образовательной программы было провели анкетирование.

Ответы на вопросы первого блока показали следующий уровень знаний: удовлетворительное знание анатомического строения органов дыхания, физиологии дыхания (2 балла), хорошее знание собственных антропометрических показателей - роста, массы тела (3 балла), хорошее знание собственных показателей гемодинамики - пульса, уровня артериального давления (3 балла), удовлетворительное знание всех управляемых факторов риска формирования и обострения астмы (2 балла), хорошее знание признаков обострения заболевания (3 балла), удовлетворительное знание принципов клинико-функционального самоконтроля за течением астмы (2 балла), удовлетворительное знание назначения таких приборов индивидуального пользования, как спейсер и пикфлоуметр (3 балла), хорошее знание принципов элиминационной терапии заболевания (3 балла), удовлетворительное знание современных лекарственных препаратов и методов лечения бронхиальной астмы (2 балла), хорошее знание ингаляционных устройств для лечения астмы (3 балла), хорошее знание принципов здорового образа жизни (3 балла), удовлетворительное знание основ диетотерапии больного бронхиальной астмой (2 балла), удовлетворительное знание принципов дыхательной гимнастики и физкультуры для больных бронхиальной астмой, закаливания (2 балла), удовлетворительное знание основ общего массажа и массажа лица (2 балла).

Анкетирование по вопросам второго блока по уровню приобретенных практических навыков и умений показало удовлетворительное владение навыком по подсчету пульса (2 балла), удовлетворительное владение навыками по подсчету частоты дыхания (2 балла), удовлетворительный уровень обучения оценки состояния по системе цветовых «зон» (2 балла), удовлетворительное владение техникой пикфлоуметрии (2 балла), хорошее умение интерпретации результатов диагностических процедур (3 балла), удовлетворительная способность пациента самостоятельно предотвращать приближающееся ухудшение в течении астмы (2 балла), хорошее владение техникой ингаляций при использовании дозированных ингаляторов, спейсеров, небулайзеров (3 балла), отсутствие дневника самонаблюдения 
(1 балл), удовлетворительное владение навыками по дыхательным методикам по методу биологически обратной связи (2 балла), отсутствие навыка по волевому управлению дыханием (1 балл), удовлетворительное владение элементами самомассажа биологически активных точек для активного использования в приступном периоде наряду с дыхательной гимнастикой (2 балла), удовлетворительное владение навыками мышечной релаксации (2 балла), удовлетворительное владение элементами аутотренинга (2 балла), удовлетворительное владение психотерапевтическими приемами (2 балла), удовлетворительное навыки по лечебной физкультуре (2 балла), хорошие навыки по составлению домашней аптечки (3 балла); удовлетворительное навыки саногенного поведения (2 балла).

Анкетирование по вопросам третьего блока по динамике течения заболевания согласно объективизированным статистическим медицинским критериям показало наличие редких приступов удушья (2 балла); отсутствие ночных приступы удушья (1 балл); 2 обострения (2 балла); отсутствие госпитализаций (1 балл); более 14 дней временной нетрудоспособности (1 балл); 2 вызова бригады «скорой помощи» (2 балла), отсутствие группы инвалидности (3 балла); ухудшение общего состояния (1 балл), средний уровень самооценки качества жизни (2 балла).

Суммируя полученные результаты, получаем 85 баллов, что позволяет оценить средний уровень качества подготовки пациента после завершения обучения в «Астма-школе».

Нами проведена оценка влияния комплексного оздоровительного воздействия на пациентов с бронхиальной астмой, включающего обучение по тематическому циклу в «Астма - школе» на эффективность превентивного лечения. Для этого нами была исследована результативность 2-х комплексов терапии:

1-я группа -пациенты с бронхиальной астмой, которые получали фармакотерапевтическое сопровождение по программе - терапии БА.

2-я группа -пациенты, которые также, как и в 1-й группе, получали комплексную базисную фармакотерапию, соответствующей клинике ступени и, наряду с этим, прослушали 2х недельную тематическую образовательную программу. Из 60-ти пациентов наблюдение обеспечено 57 пациентам.

В качестве критериев оценки результатов лечения использовалась унифицированная 5-бальная шкала (по В.С. Мошкевичу, 1985), при которой:

- оценка 5 (отличный результат) означает, что полностью или почти полностью отсутствуют жалобы и объективные симптомы заболевания. Пациенту не требуется какого-либо лечения, даже симптоматического. 
- оценка 4 (хороший результат) - значительно уменьшается (более, чем на 50\%) степень выраженности симптомов, при объективном исследовании бронхообструкция выражена слабо и количество жалоб значительно меньше. Пациент в период обострения к врачу обычно не обращается, но дополнительные лекарства иногда принимает.

- оценка 3 (удовлетворительный результат) - количество жалоб, степень выраженности объективных симптомов и продолжительность заболевания снижаются незначительно. Во время обострения пациент вынужден обращаться к врачу и получать дополнительное лечение.

- оценка 2 (плохой результат) - не обнаруживается каких-либо положительных сдвигов субъективной оценки (жалоб), степени выраженности объективных симптомов. Данное состояние можно оценить, как “без перемен”.

- оценка 1 (ухудшение) - появляются новые жалобы, симптомы заболевания усиливаются, увеличивается продолжительность обострения, выявляются осложнения со стороны других органов.

Использование приведенной выше 5-балльной шкалы позволила объективно оценить не только качественные результаты лечения, но и количественные, что становится особенно важно при применении новых методов лечения пациентов с БА.

Оценивая данные об эффективности образовательной программы в комплексной профилактике и лечении пациентов с БА по 5 бальной шкале, установили, что результаты использования образовательной программы во второй группе пациентов (сопровождающейся образовательными мероприятиями) были статистически значимо эффективнее, чем в первой ( $<<0,05)$. При комплексной фармакотерапии с использованием образовательной программы положительные результаты достигнуты у 75,4\% обследованных, а при изолированной фармакотерапии - у 58,0\% (p<0,05) (табл. 1).

Таблииа 1. Результаты оценки состояния здоровья больных БА по 5 балльной шкале, \%

\begin{tabular}{|l|c|c|c|c|}
\hline \multicolumn{1}{|c|}{ Группа больных } & $\begin{array}{c}\text { Кол-во } \\
\text { пациен- } \\
\text { тов }\end{array}$ & $\begin{array}{c}\text { Положи- } \\
\text { тельные ре- } \\
\text { зультаты }\end{array}$ & $\begin{array}{c}\text { Отлич- } \\
\text { ные }\end{array}$ & $\begin{array}{c}\text { Хоро- } \\
\text { шие }\end{array}$ \\
\hline Первая (фармакотерапия) & 50 & 58,0 & 22,0 & 36,0 \\
\hline $\begin{array}{l}\text { Вторая (фармакотерапия в комплек- } \\
\text { се с образовательной программой) }\end{array}$ & 57 & 75,4 & 24,6 & 50,8 \\
\hline
\end{tabular}


Статистически значимая разница была достигнута между пациентами первой и второй группы, результаты лечения которых оценены как хорошие $(36,0$ и $50,8 \%, \mathrm{p}<0,05)$.

Таким образом, предлагаемая методика оценки качества обучения пациентов «Астма-школы», основанная на изучении уровня теоретических знаний, качества владения практическими навыками и умениями, оценке динамики течения заболевания согласно объективизированным статистическим медицинским критериям позволяет оценить эффективности обучения пациента в «Астма-школе», развивать далее, количественно оценивая, различные варианты их обеспечения.

Авторами в доступной научно-медицинской литературе не обнаружено сведений о разработке и применении системы диагностических мероприятий по изучению информированности пациентов по уровню теоретических знаний, полученных в процессе обучения в «Астма-школе», по качеству приобретенных практических навыков и умений и по динамике течения заболевания.

\section{Выводы}

Использование разработанной методики по диагностике уровня подготовки пациента позволяет оценить эффективность обучения в «Астма-школе» и качество образовательного процесса, а через это - развивать внедрение дифференцированных образовательных программ.

\section{Список литературы}

1. Хохлов А.Л., Глембицкая О.В., Лилеева Е.Г. Оценка приверженности к терапии и качества жизни у больных с бронхиальной астмой после внедрения обучающих программ // Проблемы стандартизации в здравоохранении. 2009. № 7-8. C. 13-18.

2. Reddel H.K., Barnes D.J. Pharmacological strategies for self-management of asthma exacerbations // Eur. Respir. J. 2014. 28(1). P. 182-199.

3. Глембицкая О.В. Клинико-экономическая эффективность обучающих программ для больных бронхиальной астмой. Новости здравоохранения. 2011. №1. C. 23-30.

4. Masoli M. The global burden of asthma: executive summary of the GESfA Dissemination Committee report / M. Masoli, D. Fabian, S. Holts et al. // Alergy. 2014. Vol. 59. Р. 469-478.

5. Белевский А.С. Тест контроля астмы - «новая игрушка» или важный инструмент // Атмосфера. Пульмонология и аллергология. 2009. №1. С. 33-34. 
6. Национальная программа «Бронхиальная астма у детей. Стратегия лечения и профилактика». Второе издание. М.: Издательский дом «Русский врач». 2011. C. 87.

7. Мицкевич С.Э. Бронхиальная астма у детей. Диагностика, клиника, лечение, профилактика: Учебное пособие. Челябинск: Издательство «Челябинская государственная медицинская академия». 2012. С. 36.

8. Шарафутдинова Н.Х., Явгильдина А.М., Ганцева Х.X. Тематическая образовательная программа для больных поллинозом // Методические рекомендации для врачей-иммунологов. Уфа: Изд-во Медиа Группа Здоровье. 2011. 31 с.

\section{References}

1. Khokhlov A.L., Glembitskaya O.V., Lileeva E.G. Otsenka priverzhennosti k terapii i kachestva zhizni u bol'nykh s bronkhial'noy astmoy posle vnedreniya obuchayushchikh programm [Assessment of adherence to therapy and quality of life in patients with bronchial asthma after the introduction of training programs]. Problemy standartizatsii $v$ zdravookhranenii [Problems of standardization in healthcare]. 2009. No. 7-8. P. 13-18.

2. Reddel H.K., Barnes D.J. Pharmacological strategies for self-management of asthma exacerbations. Eur. Respir. J. 2014. 28(1). P. 182-199.

3. Glembitskaya O.V. Kliniko-ekonomicheskaya effektivnost' obuchayushchikh programm dlya bol'nykh bronkhial'noy astmoy [Clinical and economic effectiveness of training programs for patients with bronchial asthma]. Novosti zdravookhraneniya [Health News]. 2011. No. 1. P. 23-30.

4. Masoli M., Fabian D., Holts S. et al. The global burden of asthma: executive summary of the GESfA Dissemination Committee report. Alergy. 2014. Vol. 59. P. 469-478.

5. Belevsky A.S. Test kontrolya astmy - «novaya igrushka» ili vazhnyy instrument [An asthma control test is a "new toy" or an important tool]. Atmosfera. Pul'monologiya i allergologiya [Atmosphere. Pulmonology and allergology]. 2009. No. 1. P. 33-34.

6. Natsional'naya programma «Bronkhial'naya astma u detey. Strategiya lecheniya i profilaktika» [National program "Bronchial asthma in children. Treatment Strategy and Prevention"]. M.: Publishing House "Russian Doctor". 2011. P. 87.

7. Mitskevich S.E. Bronkhial'naya astma u detey. Diagnostika, klinika, lechenie, profilaktika [Bronchial asthma in children. Diagnosis, Clinic, Treatment, Prevention]. Chelyabinsk: Publishing House "Chelyabinsk State Medical Academy". 2012. P. 36.

8. Sharafutdinova N.Kh., Yavgildina A.M., Gantseva H.Kh. Tematicheskaya obrazovatel'naya programma dlya bol'nykh pollinozom [Thematic education- 
al program for patients with pollinosis] / Methodical recommendations for doctors-immunologists. Ufa: Publishing house Media Group Health. 2011. 31 p.

\section{ДАННЫЕ ОБ АВТОРАХ}

Ганцева Халида Ханафиевна, д.м.н., профессор, зав. кафедрой внутренних болезней

ФГБОУ ВО «Башкирский государственный медииинский университет» Министерства здравоохранения Российской Федерации ул. Ленина, 3, г. Уфа, Российская Федерачия halida.ganceva@mail.ru

Ханова Айритта Каримовна, к.м.н., доцент кафедры внутренних болезней ФГБОУ ВО «Башкирский государственный медицинский университет» Министерства здравоохранения Российской Федерации ул. Ленина, 3, г. Уфа, Российская Федерация

Явгильдина Альфия Мустамировна, к.м.н., доцент кафедры внутренних болезней ФГБОУ ВО «Башкирский государственный медицинский университет» Министерства здравоохранения Российской Федераџии ул. Ленина, 3, г. Уфа, Российская Федераџия

\section{DATA ABOUT THE AUTHORS}

Gantseva Khalida Khanafievna, Doctor of Medical Sciences, Professor, Head Department of Internal Medicine Bashkir State Medical University

3, Lenin st., Ufa, Russian Federation halida.ganceva@mail.ru

Khanova Ayritta Karimovna, Ph.D. (Candidate of Medicine), Assistant Professor of Internal Medicine Bashkir State Medical University

3, Lenin st., Ufa, Russian Federation

Yavgildina Alfiya Mustamirovna, Ph.D. (Candidate of Medicine), Assistant Professor of Internal Medicine Bashkir State Medical University

3, Lenin st., Ufa, Russian Federation 